\title{
BIOMECHANICAL TESTING AND FINITE ELEMENT ANALYSIS OF FIXATOR MONTAGES
}

\author{
István Kádas ${ }^{1}$, Tamás Törköly², Tamás Bíró ${ }^{2}$, Zsuzsa Bíró ${ }^{1}$, Dániel Kádas² \\ ${ }^{1}$ Péterfy Sándor Street Hospital-Clinic and Trauma Centre \\ ${ }^{2}$ Budapest University of Technology and Economics \\ drkadas@gmail.com
}

\begin{abstract}
Among the factors determining the stability of external fixator osteosyntheses the deciding factor is the configuration of the montage. The authors examined the stability of unilateral and V-forms used in crural fractures together with a Budapest University of Technology task force. They performed osteotomy on cadaver bones and used a total of 12 kinds of montage variations. The various montages were exposed to 5 types of static load, their stability was tested, and finite element model experiments were performed. The load tests were evaluated by computer and the charts were compared. It was concluded that unilateral montages are most stable when the pins are placed in the greatest possible distance from each other within one segment and the rods are far from each other. In case of V-frame symmetrically inserted pins should be avoided in the second plane for better stability. Finite element model has verified the biomechanical observations. During the biomechanical experiment the authors have gained useful experiences for further clinical practice.
\end{abstract}

Keywords: external fixator, tibial fracture, finite element analysis, comparative study, fixator montage, biomechanical analysis

\section{Introduction}

In case of bone fractures the person's inner statical support structure gets injured. As a result of the muscles'draught the limb shortens, and the fracture dislocates. If inner osteosynthesis is not desirable because of soft tissue injury an outer statical frame: external fixator is used. Outer frames are different from inner syntheses, they are less stable but their effect on the fracture can be modified in space and time. Among the factors determining the stability of fixator osteosyntheses the deciding factor is the configuration of the montage $e^{1,2,3,4,5}$. We examined the stability of unilateral and V-frames in crural fractures together with a Budapest University of Technology task force in a biomechanics laboratory ${ }^{6,7}$. The various montages were exposed to static load using the same method, and shifts were examined. At the end finite element model experiments were performed ${ }^{8}$.

Planning:

1. Montage planning

2. Course of the study

3. Measurement planning

4. Comparision of results

\section{Method}

Elements of the fixator montage:

1. Position of pins within the shin and within the segment

2. Position of rods as compared to the pins and each other

3. Properties of the linking element

4. Montage variations 
1. According to the theory ideal pin position in case of unilateral frame is determined by the soft tissue coating. While in the past frame forms were used that were pierced through actively moving muscle elements today we aim the anterior medial surface of the tibia, avoiding the soft tissue coating. The pins are inserted in the sagittal plane, in line with each other. The position of two pins within a segment can be distant or close. In the distant type one of the pins inserted in the same plane is situated closest to the fracture and the other is furthest. In the other type the two pins are inserted close to each other (Figure 1). The latter type is used by many fixator systems (Hoffmann-Vidal, AO-Synthes double clamp) $9,10,11,12$.

2. Position of the rods was also examined. Two rods were mounted on the pins in two different ways. In the distant type one of the rods was placed closest to the skin while the other the furthest. In the close type the two rods were placed close to each other. Another condition was also examined. In one group both rods

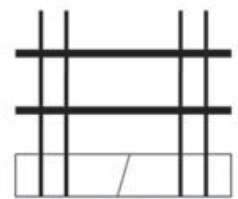

close

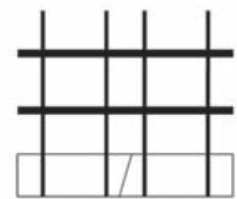

far
Figure 1. The compared position of pins

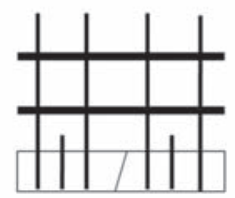

symmetrical

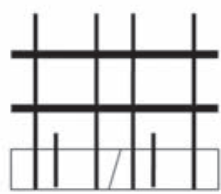

asymmetrical

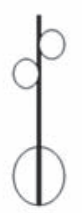

close

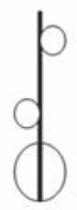

far

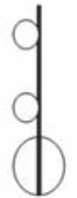

same side

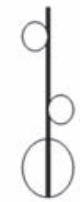

opposite side
Figure 2. The compared position of rods

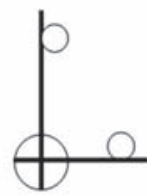

inner side

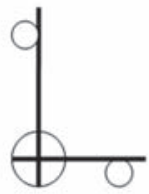

outer side

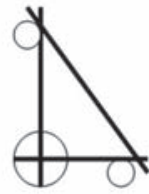

crossbars
Figure 3. Position of the pins in plane 


\section{Preparation of bone samples}

Oblique osteotomy of 45 degrees was made on cadaver tibias, and then unilateral frame was mounted in the sagittal plane. The two pins in the same segment were inserted in two different distances (Figure 1). The pins were connected by rods. Three configurations were used in the rod positions: close to the bone, furthest from the bone and same side or opposite sides of the pins. In the other main group V-frames with various pin positions were mounted. The pins of the second plane were either inserted in the midpoint or far away from it, asymmetrically. The rods were placed on either the inner or the outer side of the $\mathrm{V}$-shape. At the end the longitudinal rod-system was connected by crossbars. By this method we created 12 types of montages.

\section{Materials and methods}

\section{Measurement of the stability of crural external fixator montages}

The montages were exposed to comparative study. Five types of static load were used: axial, varus and valgus stress, recurvation and antecurvation. Dislocation was examined in the level of osteotomy. Our first idea was detection using an optical camera but that wasn't accurate enough. We tried to use pressure stamps built between the fracture surfaces but those didn't work either. Thus we got to use indicator gauges detecting shift with $0.01 \mathrm{~mm}$ accuracy. The rod system of the gauges was fixed using fixator pins in a preset distance from the fracture, on both sides of the fracture. We calculated the shift projected to the fracture plane using mathematical formulas. The shift along the axis was tested by axial load, and the load was increased by $10 \mathrm{~N}$ each time. For further tests one end of the sample was fixed, and weights were hanged on the other end; the load was increased by $10 \mathrm{~N}$ each time. The shifts were detected by 4 gauges in specific positions. Bending and rotation were measured in two planes perpendicular to each other.

The tests were performed in the Biomechanical Laboratory of the Budapest University of Technology.

\subsection{Aim of the measurement}

The external fixator montages mounted on preparated (osteotomy) cadaver tibiae were exposed to various loads (axial, valgus, varus, antecurvation, recurvation), and the relative shift and relative rotation between the fracture surfaces were measured.

\subsection{Measurement process}

One end of the tibia was rigidly clamped while the other end was exposed to gradually increasing load. Relative shift between the fracture surfaces was measured as a function of the force used.

A mechanical system was used for measurement with indicator gauges of $0.01 \mathrm{~mm}$ accuracy (Figure 5).

Both ends of the cadaver tibia were stuck into a metal basket using epoxy resin. The proximal end was rigidly fixed by a metal clamp,

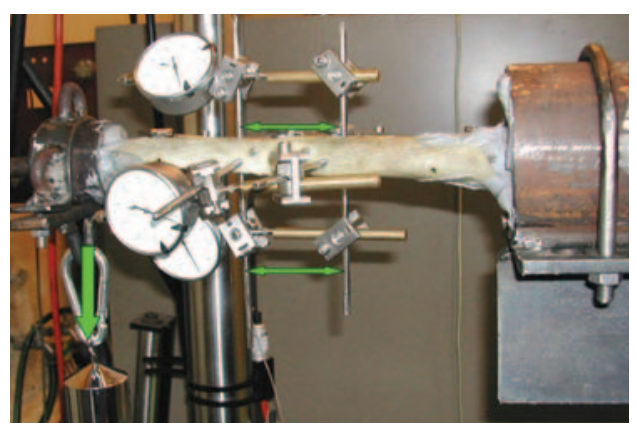

Figure 5. Measuring disposition 
and then we hanged weights on the distal end. Four gauges were installed. The gauges were fixed to a preset distance from the plane of osteotomy (fracture gap) by 2 Schanz screws. The instrument measured the shift between the two Schanz screws by $0.01 \mathrm{~mm}$ accuracy. The shift projected to the plane of osteotomy was calculated from the measured data using mathematical formulas.

\section{Interpretation of experiment parameters}

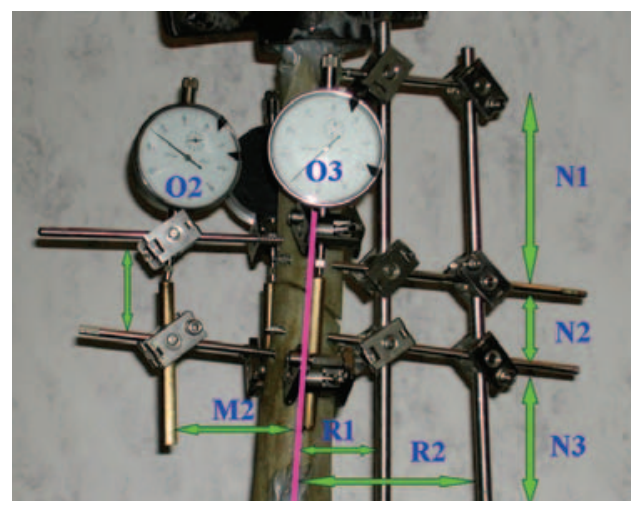

Figure 6. Measuring parameters I.

Figure 6, 7 show the geometrical parameters of the montage used in the study $(\mathrm{N}, \mathrm{R})$, the position of the gauges $(\mathrm{O})$ and the relative shift measured by the gauges $(\mathrm{M})$.

$\mathrm{N} 1,2,3$ - distance between pins

$\mathrm{R} 1,2$ - distance between the rods and the midline of the bone

M1,2,3,4 - distance between the gauges and the midline of the bone

O1,2,3 - relative shift of gauges in signed numbers

The number of possible variations is 12 . Each

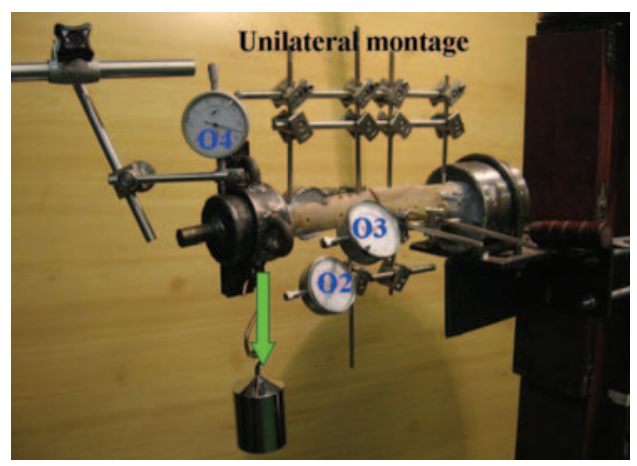

Figure 7. Measuring parameters II.

\begin{tabular}{|c|l|c|c|c|c|c|}
\hline & & & & & & \\
& & & & & \\
& & & & & \\
& & & & & \\
& & $\mathrm{X}$ & $\mathrm{X}$ & & \\
\hline 1. & Unilateral, pins close & $\mathrm{X}$ & $\mathrm{X}$ & $\mathrm{X}$ & $\mathrm{X}$ & $\mathrm{X}$ \\
\hline 2. & Unilateral, pins far & $\mathrm{X}$ & $\mathrm{X}$ & $\mathrm{X}$ & $\mathrm{X}$ & $\mathrm{X}$ \\
\hline 3. & Unilateral, rods close & $\mathrm{X}$ & $\mathrm{X}$ & $\mathrm{X}$ & $\mathrm{X}$ & $\mathrm{X}$ \\
\hline 4. & Unilateral, rods far & $\mathrm{X}$ & $\mathrm{X}$ & $\mathrm{X}$ & $\mathrm{X}$ & $\mathrm{X}$ \\
\hline 5. & Unilateral, rods same side & $\mathrm{X}$ & $\mathrm{X}$ & $\mathrm{X}$ & $\mathrm{X}$ & $\mathrm{X}$ \\
\hline 6. & Unilateral, rods opposite side & $\mathrm{X}$ & $\mathrm{X}$ & $\mathrm{X}$ & $\mathrm{X}$ & $\mathrm{X}$ \\
\hline 7. & V-shape, pins in the midline & $\mathrm{X}$ & $\mathrm{X}$ & $\mathrm{X}$ & $\mathrm{X}$ & $\mathrm{X}$ \\
\hline 8. & V-shape, close to fracture & $\mathrm{X}$ & $\mathrm{X}$ & $\mathrm{X}$ & $\mathrm{X}$ & $\mathrm{X}$ \\
\hline 9. & V-shape, far from fracture & $\mathrm{X}$ & $\mathrm{X}$ & $\mathrm{X}$ & $\mathrm{X}$ & $\mathrm{X}$ \\
\hline 10. & V-shape, rod in the inner side & $\mathrm{X}$ & $\mathrm{X}$ & $\mathrm{X}$ & $\mathrm{X}$ & $\mathrm{X}$ \\
\hline 11. & V-shape, rod in the outer side & $\mathrm{X}$ & $\mathrm{X}$ & $\mathrm{X}$ & $\mathrm{X}$ & $\mathrm{X}$ \\
\hline 12. & V-shape + crossbars & & & & $\mathrm{X}$ \\
\hline
\end{tabular}

Table 1. ' $\mathrm{X}$ ' is for measurements that were performed. Red indicates the variation of pin positioning, black indicates the variation of rod positioning" 
montages were exposed to 5 types of load, therefore 60 measurements were performed. The tests were repeated on 5 cadaver tibiae, and then the mean value was calculated. The variations are summarized in a table (Table 1).

\section{Configuration of the tested montages}

Detailed discussion on each variations would be beyond the confines of this study, therefore here we present only 6 measurements of the 12 considered as significant.

\subsection{Configuration of unilateral montage No. 1: N: far, R: far, same}

The pins are positioned in the greatest possible distance from each other, that is one pin is placed as close to the fracture as possible ( $\mathrm{N} 2=42 \mathrm{~mm}$ ) and the other is placed as far as possible $(\mathrm{N} 1=\mathrm{N} 3=84 \mathrm{~mm})$.

Position of the rods: As close to the bone as possible $(\mathrm{R} 1=45 \mathrm{~mm})$ and as far as possible $(\mathrm{R} 2=90 \mathrm{~mm})$, and the rods are positioned on the same side of the pin (Figure 8).

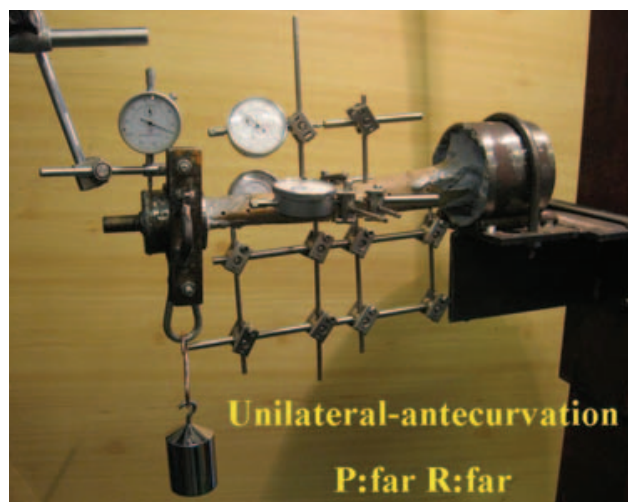

Figure 8. Montage variation Unilat P: far R: far, same

\subsection{Configuration of unilateral montage} No. 2: N: far, R: far, opposite

The pins are positioned in the greatest possible distance from each other, that is one pin is placed as close to the fracture as possible $(\mathrm{N} 2=42 \mathrm{~mm})$ and the other is placed as far as possible $(\mathrm{N} 1=\mathrm{N} 3=84 \mathrm{~mm})$.

Position of the rods: As close to the bone as possible $(\mathrm{R} 1=45 \mathrm{~mm})$ and as far as possible $(\mathrm{R} 2=90 \mathrm{~mm})$, and the rods are positioned on opposite sides of the pin (Figure 9).

\subsection{Configuration of unilateral montage No. 3: N: far, R: close, opposite}

The pins are positioned in the greatest possible distance from each other, that is one pin is placed as close to the fracture as possible $(\mathrm{N} 2=42 \mathrm{~mm})$ and the other is placed as far as possible $(\mathrm{N} 1=\mathrm{N} 3=84 \mathrm{~mm})$.

Position of the rods: As close to the bone as possible $(\mathrm{R} 1=45 \mathrm{~mm})$ and close to each other $(\mathrm{R} 2=65 \mathrm{~mm})$, and the rods are positioned on opposite sides of the pin.

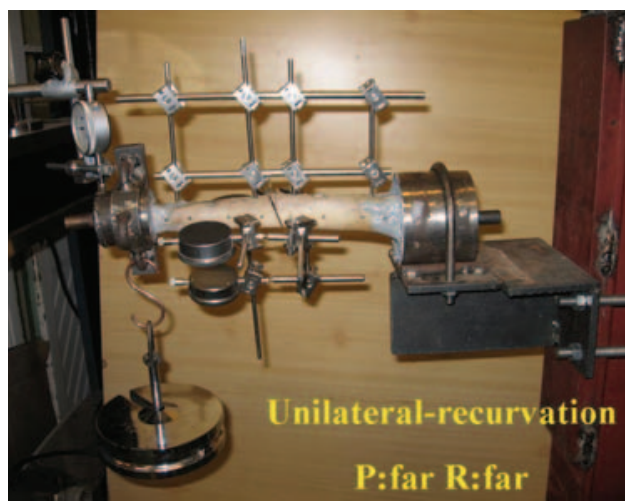

Figure 9. Montage variation Unilat P: far R: far, opposite 


\subsection{Configuration of unilateral montage No. 4: N: far, R: close, opposite}

The pins are positioned in the greatest possible distance from each other, that is one pin is placed as close to the fracture as possible $(\mathrm{N} 2=42 \mathrm{~mm})$ and the other is placed as far as possible $(\mathrm{N} 1=\mathrm{N} 3=84 \mathrm{~mm})$.

Position of the rods: As far from the bone as possible $(\mathrm{R} 1=65 \mathrm{~mm})$ and close to each other $(\mathrm{R} 2=90 \mathrm{~mm})$, and the rods are positioned on opposite sides of the pin.

\subsection{Configuration of unilateral montage No. 5: N: close, R: far, opposite}

The pins are positioned as close to each other as possible, that is one pin is placed as close to the fracture as possible $(\mathrm{N} 2=42 \mathrm{~mm})$ and the other is placed as close to the first pin as possible $(\mathrm{N} 1=\mathrm{N} 3=24 \mathrm{~mm})$.

Position of the rods: As close to the bone as possible $(\mathrm{R} 1=45 \mathrm{~mm})$ and as far as possible $(\mathrm{R} 2=90 \mathrm{~mm})$, and the rods are positioned on opposite sides of the pin (Figure 10).

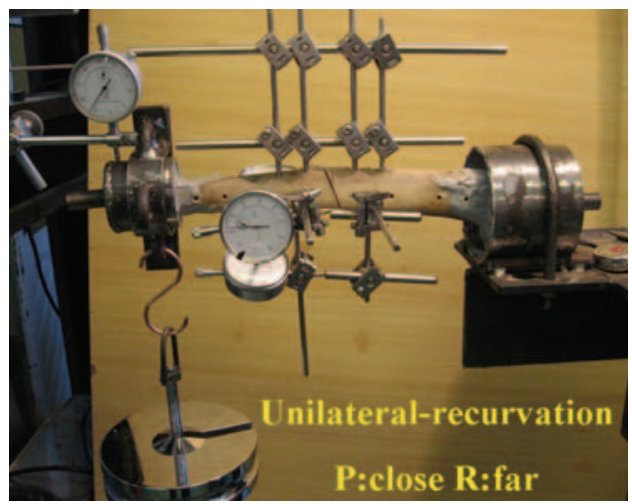

Figure 10. Montage variation Unilat P: close R: far, opposite

\subsection{Configuration of V-frame montage No. 6: N: far, R: far, opposite 2nd plane: $N$ : far, $R$ : far, same}

The pins are positioned in the greatest possible distance from each other, that is one pin is placed as close to the fracture as possible $(\mathrm{N} 2=42 \mathrm{~mm})$ and the other is placed as far as possible $(\mathrm{N} 1=\mathrm{N} 3=84 \mathrm{~mm})$. The pins of the second plane are also positioned in the furthest possible distance from each other, that is one pin is placed as close to the fracture as possible $(\mathrm{N} 2=54 \mathrm{~mm})$ and the other is placed as far as possible $(\mathrm{N} 1=\mathrm{N} 3=90 \mathrm{~mm})$.

Position of the rods: As close to the bone as possible $(\mathrm{R} 1=45 \mathrm{~mm})$ and as far as possible $(\mathrm{R} 2=90 \mathrm{~mm})$, and the rods are positioned on opposite sides of the pin. The rods of the second plane are also placed like this: closest to the bone ( $\mathrm{R} 1=45 \mathrm{~mm})$ and furthest from the bone $(\mathrm{R} 2=90 \mathrm{~mm})$, and the rods are positioned on the same side of the pin. The rods are connected with crossbars (Figure 11).

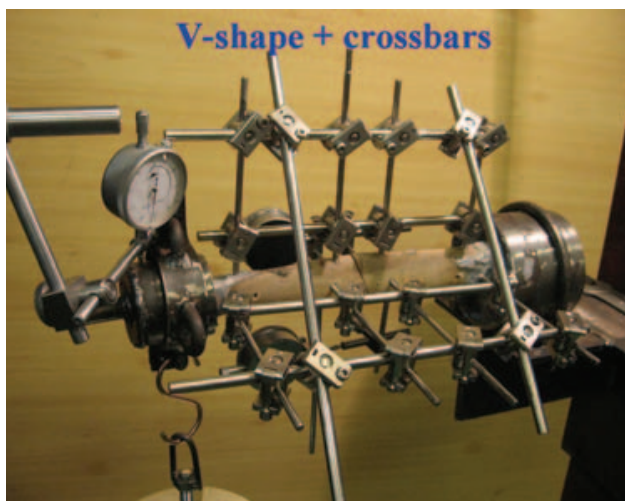

Figure 11. Montage variation Unilat P: far R: far, opposite

Plane 2 P: far R: far, opposite 


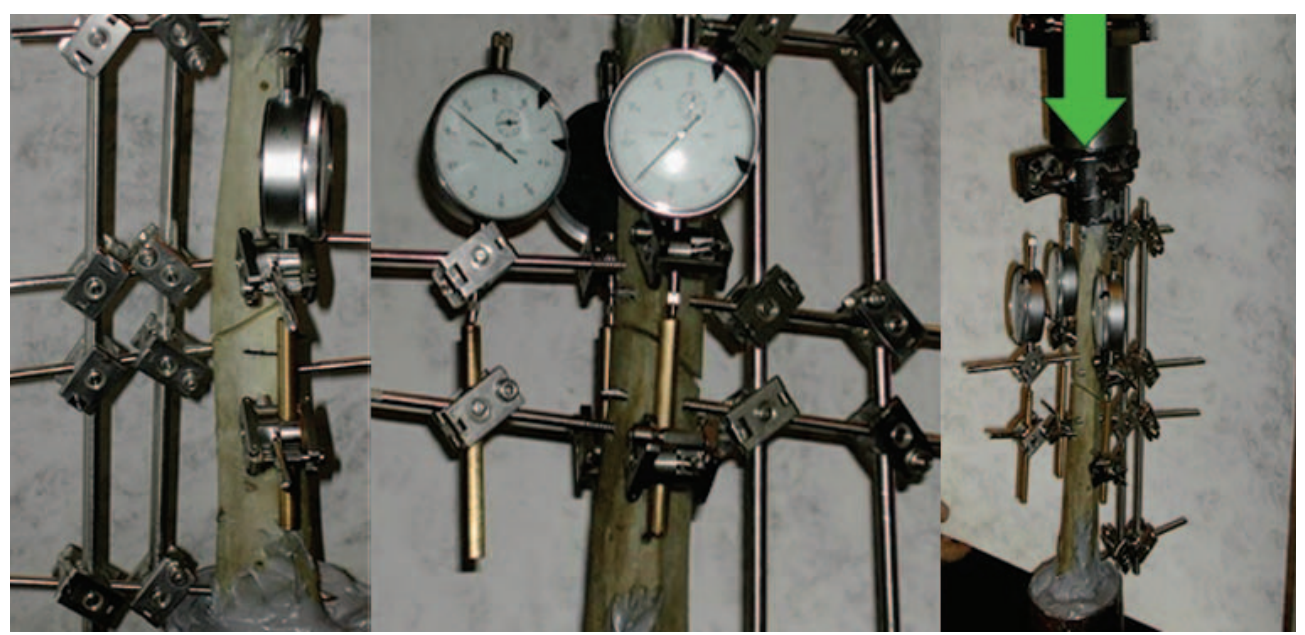

Figure 12. Axial strain Meter: O1-O2-O3

\section{Load types}

\subsection{Axial load}

The sample was posted on its end covered by the larger cup and was fixed. The other end was gradually loaded along the axis of the bone (axial load). In this case the data detected by the gauges No. 1, 2 and 3 were recorded (Figure 12).

\subsection{Bending}

The stress falling on the fixator montage is best modeled by force perpendicular to the bone axis. The force axis of unilateral and V-frames we used are not aligned with the bone axis therefore torque occurs in the fixator combination. By exposing various montages to similar load we could establish a stability order among the variations. That's how we could tell which is the most stable form.

\subsubsection{Valgus}

The unilateral montage inserted in the saggital plane can be loaded in 4 main directions. The first test was pressing away from the body

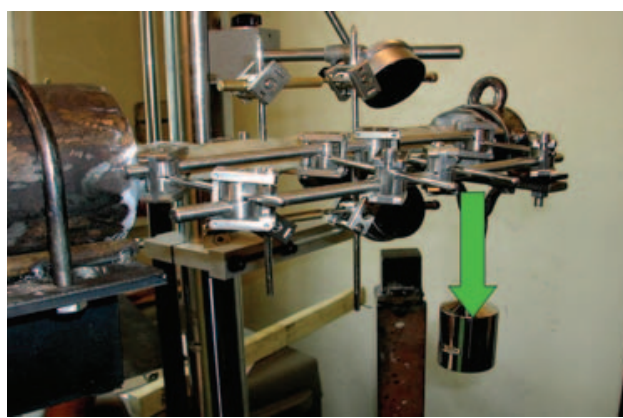

Figure 13. Valgus strain Meter: O1-O2-O3-O4

midline that is valgus stress. The load weight was increased by $10 \mathrm{~N}$ each time and shift was registered on all 4 gauges (Figure 13).

\subsubsection{Varus}

The second test was the opposite of the first one that is the distal end of the tibia was pressed in the direction of the body midline. In this case also 4 gauges were used (Figure 14).

\subsubsection{Antecurvation}

For forward bending - antecurvation - the fixator inserted in the sagittal plane was exposed to bending force in the sagittal plane 


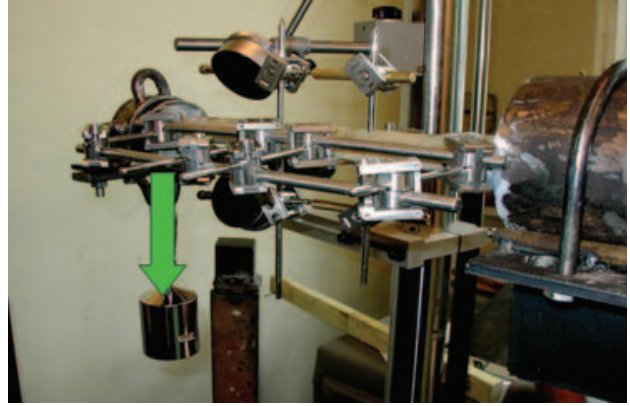

Figure 14. Varus strain Meter: O1-O2-O3-O4

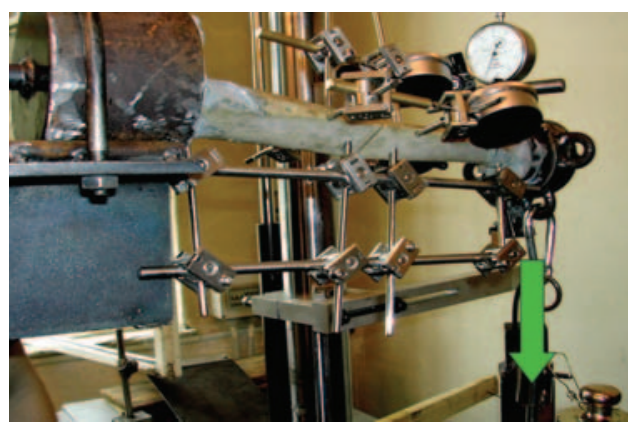

Figure 16. Recurvation strain Meter:

$\mathrm{O} 1-\mathrm{O} 2-\mathrm{O} 3-\mathrm{O} 4$

trending towards the dorsal direction and shift was recorded (Figure 15).

\subsubsection{Recurvation}

For backward bending - recurvation - the fixator inserted in the sagittal plane was exposed to bending force in the sagittal plane trending towards the ventral direction and shift was recorded (Figure 16).

\section{Calculated data}

It is laborious to measure fracture surfaces and it gives a less accurate number therefore the extent of shift was measured further away each

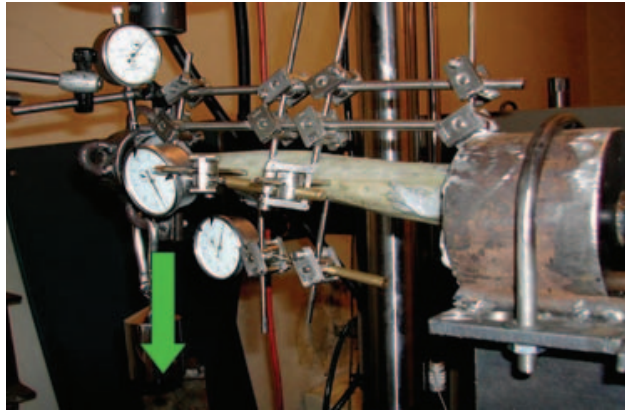

Figure 15. Antecurvation strain Meter: $\mathrm{O} 1-\mathrm{O} 2-\mathrm{O} 3-\mathrm{O} 4$

case and it was converted to the fracture site. Letters of the formulas are indicated on figures of measurement settings. Values are given in millimetres (Figure 7, 8, 9).

$\mathrm{N} 1,2,3$ - distance between pins

R1,2 - distance between rods and bone midline

M1,2,3,4 - distance between gauges and bone midline

O1,2,3 - signed relative shift of gauges

\subsection{Calculation of axial shift between} fracture surfaces

Axial shift calculated in planes 1 and 3

$$
\mathrm{t} 1-3=\frac{(\mathrm{O} 1-\mathrm{O} 3) \times \mathrm{M} 1}{\mathrm{M} 1+\mathrm{M} 3}+\mathrm{O} 1
$$

Axial shift calculated in plane 2

$$
\mathrm{t} 2=\frac{\mathrm{R} 1}{\mathrm{R} 1+\mathrm{M} 2} \times \mathrm{O} 2
$$

Axial shift

$$
\mathrm{t}=\frac{\mathrm{t} 1-3+\mathrm{t} 2}{2} 1
$$




\subsubsection{Calculation of rotation between} fracture surfaces

Rotation calculated in planes 1 and 3

$$
\mathrm{S} 1-3=\operatorname{arctg} \frac{\mathrm{O} 1-\mathrm{O} 3}{\mathrm{M} 1+\mathrm{M} 3}
$$

Rotation calculated in plane 2

$$
\mathrm{S} 2=\operatorname{arctg} \frac{\mathrm{O} 2}{\mathrm{M} 2+\mathrm{R} 1}
$$

\section{Evaluation of measurements}

Results of measurements are shown in the Table 3. The header contains montage parameters. The frame, the position of pins and rods and the distance between them are specified. Linearly increasing load was recorded and the gauges were read after each step. The table contains calculated shifts as a function of load which was increased step-by-step by $10 \mathrm{~N}$. The diagram shows signed values of axial shift between fracture surfaces for various montages (1-4) and various loads (axial, valgus, varus, antecurvation, recurvation). Positive shift stands for distancing between fracture surfaces.

The recorded data was charted. The 6 different montages were charted with 5 types of load. $4 \times 5-1$ charts were prepared. The montages were represented by different colors. The load types were distinguished by signs on the chart curves (Diagram 1, 2, 3). The following table shows the notation (Table 2).

\begin{tabular}{|l|}
\hline Color of montage: \\
\hline 1 N: far, R: far, same - red rombus \\
\hline 2 N: far, R: far, opposite - yellow square \\
\hline 3 N: far, R: close, same - yellow triangle \\
\hline 4 N: far, R: close, opposite - cyan blue X \\
\hline 5 N: close, R: far, opposite - dark blue X \\
\hline 6 V-frame, N: far, R: far, opposite - purple rombus \\
\hline
\end{tabular}

Table 2. Range of colors for montages

\section{Results}

Aspects of evaluation:

- axial shift

- rotation in planes $\mathrm{S} 1$ and 3

- rotation in plane S2

- bending

Each shift types were charted by 5 load types. First we show axial shift during axial load, recurvation, inward bending, antecurvation and outward bending. This is followed by another 5 charts of shift in planes $\mathrm{S} 1$ and 3 as a result of 5 types of load. The charting continues with plane S2 and bending. It is understandable that during the test for bending axial load wasn't used therefore one chart is missing from the last series.

It is apparent that as a result of axial pressure the distance between fracture surfaces decreases. The montages No. 1, 2 and 3 are much more rigid than No. 4 and 5 . On the graphic charts we see that purple and cyan blue curves show the largest shifts that is these frames are less stable. The most conspicouos in the bending chart series is montage No. 5 showing significant shift and bending for each load types.

\section{Finite element analysis ${ }^{20,21,22,23}$}

The aim of the analysis was to find the most stable fixator montage. The entire analysis is beyond the confines of this study. The four most important montage types were pointed out. Based on static aspects and fixation techniques of the unilateralis montages there are two main aspects of analysing the different montages.

The first aspect of comparision is the position of fixator pins correlated to each other and the fracture. 


\begin{tabular}{|c|c|c|c|c|c|}
\hline & Montage & Axial shift & Rot. S1-S3 & Rot. S2 & Bending \\
\hline \multirow{6}{*}{ 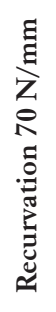 } & $1 \mathrm{~N}$ : far, R: far, same & 0.34 & 0.13 & 0.11 & 0.35 \\
\hline & $2 \mathrm{~N}$ : far, R: far, opposite & 0.17 & 0.11 & 0.10 & 0.22 \\
\hline & $3 \mathrm{~N}$ : far, R: close, same & 0.58 & 0.22 & 0.20 & 0.64 \\
\hline & $4 \mathrm{~N}$ : far, R: close, opposite & 0.68 & 0.31 & 0.28 & 0.74 \\
\hline & $5 \mathrm{~N}$ : close, R: far, opposite & 1.2 & 0.56 & 0.50 & 1.3 \\
\hline & $6 \mathrm{~V}$-frame, N: far, R: far, opposite & 0.11 & 0.07 & 0.06 & 0.19 \\
\hline \multirow{6}{*}{ 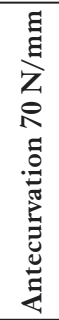 } & $1 \mathrm{~N}$ : far, R: far, same & 0.35 & 0.15 & 0.12 & 0.39 \\
\hline & $2 \mathrm{~N}$ : far, R: far, opposite & 0.19 & 0.13 & 0.12 & 0.17 \\
\hline & $3 \mathrm{~N}$ : far, R: close, same & 0.58 & 0.25 & 0.23 & 0.58 \\
\hline & $4 \mathrm{~N}$ : far, R: close, opposite & 0.64 & 0.37 & 0.34 & 0.71 \\
\hline & $5 \mathrm{~N}$ : close, R: far, opposite & 1.4 & 0.58 & 0.60 & 1.6 \\
\hline & $6 \mathrm{~V}$-frame, N: far, R: far, opposite & 0.16 & 0.12 & 0.09 & 0.18 \\
\hline \multirow{6}{*}{ 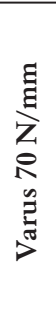 } & $1 \mathrm{~N}$ : far, R: far, same & 0.43 & 0.23 & 0.23 & 0.44 \\
\hline & $2 \mathrm{~N}$ : far, R: far, opposite & 0.24 & 0.21 & 0.21 & 0.24 \\
\hline & $3 \mathrm{~N}$ : far, R: close, same & 0.68 & 0.31 & 0.32 & 0.62 \\
\hline & 4 N: far, R: close, opposite & 0.76 & 0.40 & 0.41 & 0.77 \\
\hline & $5 \mathrm{~N}$ : close, R: far, opposite & 1.9 & 0.64 & 0.66 & 1.9 \\
\hline & $6 \mathrm{~V}$-frame, N: far, R: far, opposite & 0.15 & 0.17 & 0.17 & 0.21 \\
\hline \multirow{6}{*}{ 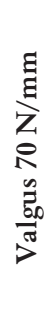 } & $1 \mathrm{~N}$ : far, R: far, same & 0.48 & 0.28 & 0.29 & 0.48 \\
\hline & $2 \mathrm{~N}$ : far, R: far, opposite & 0.29 & 0.24 & 0.27 & 0.28 \\
\hline & $3 \mathrm{~N}$ : far, R: close, same & 0.73 & 0.36 & 0.36 & 0.67 \\
\hline & $4 \mathrm{~N}$ : far, R: close, opposite & 0.79 & 0.44 & 0.48 & 0.79 \\
\hline & $5 \mathrm{~N}$ : close, R: far, opposite & 2.4 & 0.69 & 0.69 & 2.4 \\
\hline & $6 \mathrm{~V}$-frame, $\mathrm{N}$ : far, R: far, opposite & 0.15 & 0.19 & 0.19 & 0.25 \\
\hline \multirow{6}{*}{ 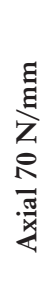 } & $1 \mathrm{~N}$ : far, R: far, same & 1.43 & 0.93 & 0.63 & 0 \\
\hline & $2 \mathrm{~N}$ : far, R: far, opposite & 1.14 & 0.81 & 0.71 & 0 \\
\hline & $3 \mathrm{~N}$ : far, R: close, same & 1.38 & 0.91 & 0.82 & 0 \\
\hline & $4 \mathrm{~N}$ : far, R: close, opposite & 1.71 & 0.80 & 0.93 & 0 \\
\hline & $5 \mathrm{~N}$ : close, R: far, opposite & 2.9 & 0.94 & 0.95 & 0 \\
\hline & $6 \mathrm{~V}$-frame, $\mathrm{N}$ : far, R: far, opposite & 0.65 & 0.37 & 0.47 & 0 \\
\hline
\end{tabular}

Table 3. Measure of shift in millimeters at $70 \mathrm{~N}$ 


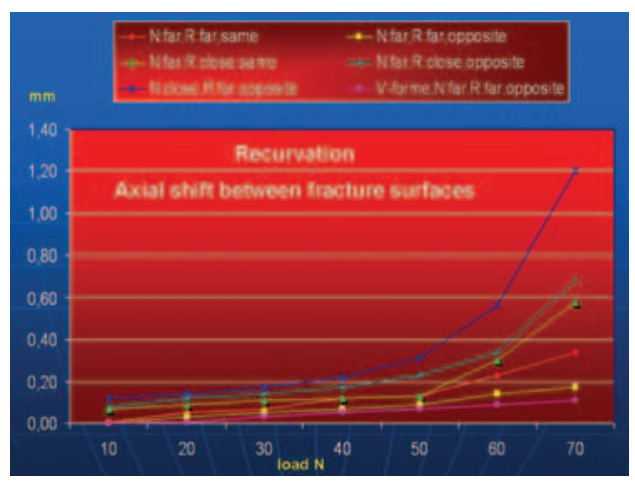

Diagram 1. Axial shift between fracture surfaces

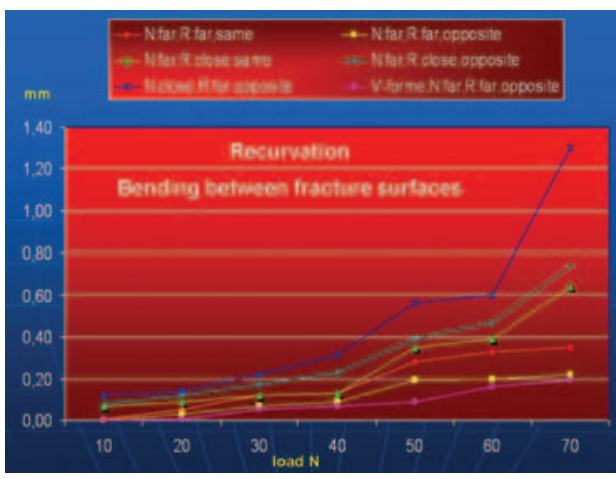

Diagram 3. Bending between fracture surfaces

Two forms are distincted in virtue of this:

- The pins in the fracture segments are in the largest possible distance from each other (pin - far)

- The pins in the fracture segments are relatively close to each other (pin - close)

The other aspect of comparision is the position of rods connecting the pins correlated to each other.

- The rods are far from each other ( rod - far)

- The rods are close to each other $(\operatorname{rod}-$ close $)$

Considering these aspects we analysed four settings in our study. During the analysis the given parameter was a force of $100 \mathrm{~N}$

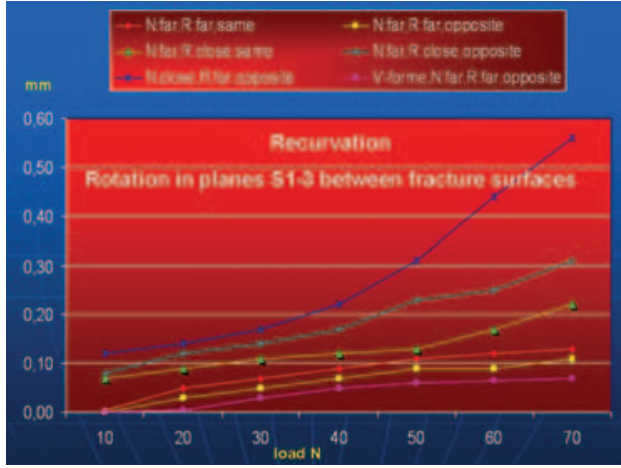

Diagram 2. Rotation in planes S1-3 between fracture surfaces

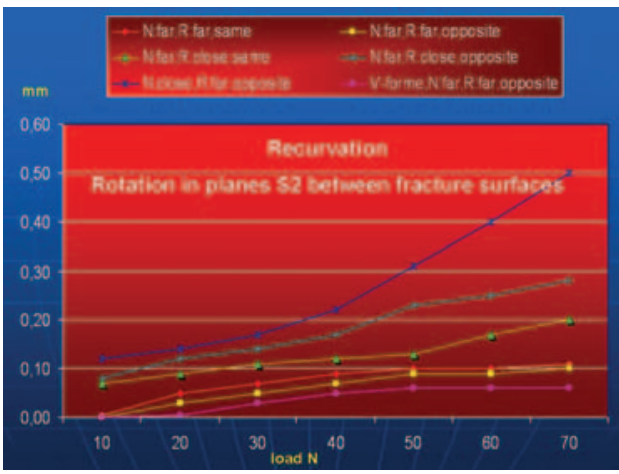

Diagram 4. Rotation in planes S2 between fracture surfaces

perpendicular to the longitudinal axis of the bone but parralel with the montage.

Running the finite element analysis we found the following results:

1. The pins are positioned close to the fracture and far from each other; the rods are close to each other (Figure 17).

If the stiffener rods are close to each other then the maximal shift by $100 \mathrm{~N}$ force is $3.48 \mathrm{~mm}$.

2. The pins are positioned close to the fracture and far from each other; the rods are far from each other (Figure 18).

If the stiffener rods are far from each other 
then the maximal shift by $100 \mathrm{~N}$ force is $3.46 \mathrm{~mm}$.

3. The pins are positioned far from the fracture but close to each other within the two fracture segments; the rods are close to each other (Figure 19).

If the pins and the stiffener rods are close to each other then the maximal shift by $100 \mathrm{~N}$ force is $6.018 \mathrm{~mm}$.

4. The pins are positioned far from the fracture but close to each other within the two fracture segments; the rods are far from each other (Figure 20).

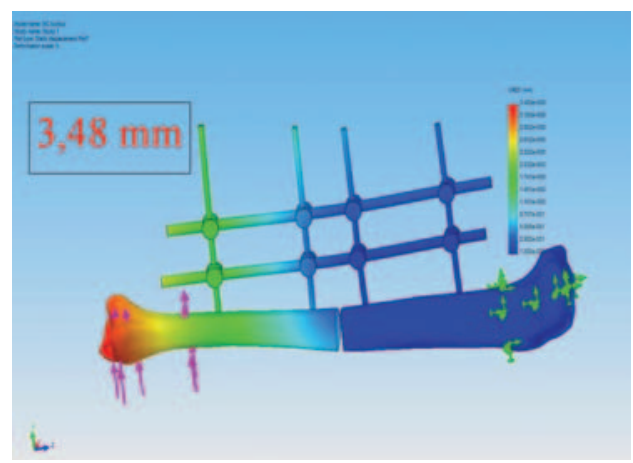

Figure 17. Montage variation Unilat P: far R: close, opposite

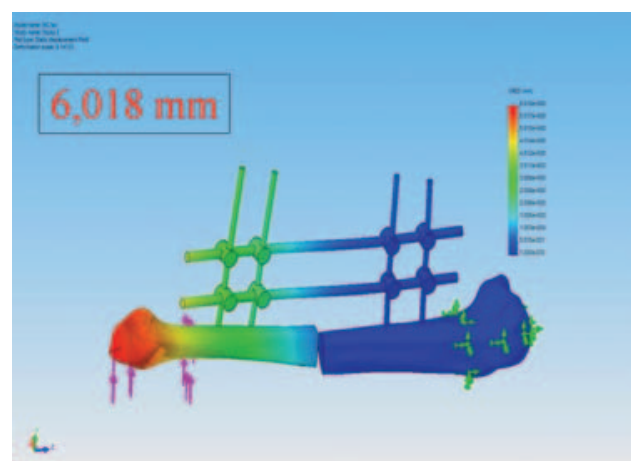

Figure 19. Montage variation Unilat.

P: close R: close, opposite
If the stiffener rods are far from each other then the maximal shift by $100 \mathrm{~N}$ force is $5.35 \mathrm{~mm}$.

\section{Discussion}

During the study we found what we expected in advance namely, that if the pins are positioned close to the fracture and far from each other the significant difference is seen in comparision with the further position. Contrarily, the position of rods has less impact on stability but it can be stated that based on physical considerations it is favorable to position the rods far from each other.

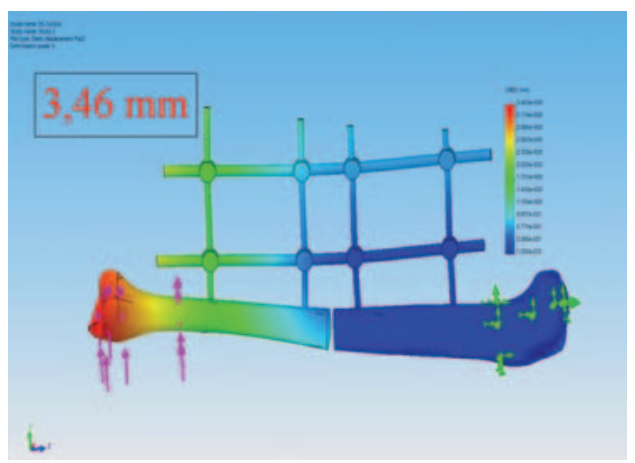

Figure 18. Montage variation Unilat P: far R: far, opposite

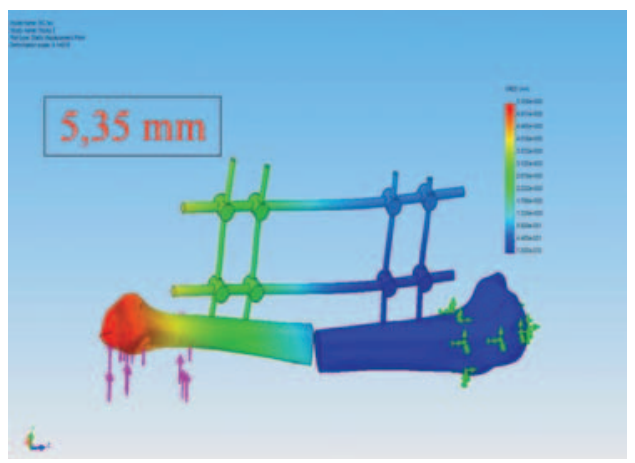

Figure 20. Montage variation Unilat P: close R: far, opposite 
Naturally, these theoretical calculations do not give a perfect insight into the behavior of fixator montages but they correlate very well with biomechanical studies and measurements.

The stable fixator montage form defined in this experiment can be very effectively used in clinical practice. The first step of treatment in case of open crural fractures is immobilization by fixator then, after the soft tissue healing another fixation form is chosen (bone nail, plate $)^{24,25,26,27,28,29,30}$. Best results can be achieved in the treatment of open crural fractures by using combined methods e.g. fixator + bone nail, fixator + plate.

\section{REFERENCES}

1. Paoli PA. The AO/ASIF external fixation system. large external fixator. Synthes 1990.

2. Tencer $A F$, Johnson $K D$. Biomechanics in orthopedic trauma: bone fracture and fixation. London: Dunitz; 1994.

3. Kádas I, Fröhlich P. A fixateur externek szerkezete. Magyar Traumatológia, Ortopédia, Kézsebészet, Plasztikai Sebészet;35(5):479-85.

4. Kádas I. Fixateur externe. In: Renner A, editor. Traumatológia. Budapest: Medicina Kiadó; 2000.

5. Kádas I, Fröhlich P. A fixateur szerkezetek statikája és annak hatása a törésgyógyulásra. Traumatológia - Témakörök - „Fixateur externe”. Országos Traumatológiai Intézet kiadványa 1993.

6. Kádas I, Árva G, Kovács G. Szerkezeti típusok és azok szerelése. Traumatológia - Témakörök „Fixateur externe”. Országos Traumatológiai Intézet kiadványa 1993.

7. Kádas I, Fröhlich P, Magyari Z. Die progressive dynamisierung in experiment und praxis. Budapest: Aesculart Verlag;1992.

8. Thordarson DB, Markolf KL, Cracchiolo A. External fixation in arthrodesis of the ankle. A biomechanical study comparing a unilateral frame wieht a modified transfixion frame. J Bone Joint Surg Am 1994;76:1541-51.

9. Calhoun JH, Li F, Ledbetter BR, Gill CA. Biomechanics of the Ilizarov fixator for fracture fixation. Clin Orthop Relat R 1992 Jul;(280): 15-22.

10. Juan JA, Prat J, Vera P, Hoyos JV, SanchezLacuesta J, Peris JL et al. Biomechanical consequences of callus development in Hoffmann, Wagner, Orthofix and Ilizarov external fixators. J Biomech 1992 Sep;25(9):995-1006.

11. Pettine KA, Chao EYS, Kelly PJ. Analysis of the external fixator pin bone interface. Clin Orthop Relat R 1993 Aug;(293):18-27.

12. Aro HT, Hein TJ, Chao EYS. Mechanical performance of pin clamps in external fixators. Clin Orthop Relat R 1989 Nov;(248):246-53.

13. Aro HT, Markel MD, Chao EYS. Cortical bone reactions at the interface of external fixation half-pins under different loading conditions. J Trauma 1993 Nov;35(5):776-85.

14. Chao EY, Kasman RA, An KN. Rigidity and stress analyses of external fracture fixation devices - a theoretical approach. J Biomech 1982; 15(12):971-83.

15. Kasman RA, Chao EY. Fatigue performance of external fixator pins. J Orthop Res 1984;2(4): 377-84.

16. Kristiansen T, Fleming B, Reinecke S. Comparative-study of fracture gap motion in external fixation. Clin Biomech 1987 Nov;2(4):191-5.

17. Lavini FM, Brivio LR, Leso P. Biomechanical factors in designing screws for the Orthofix 
system. Clin Orthop Relat R 1994 Nov;(308): 63-7.

18. Lewallen DG, Chao EYS, Kasman RA, Kelly PJ. Comparison of the effects of compression plates and external fixators on early bone-healing. J Bone Joint Surg Am 1984;66A(7):1084-91.

19. Goodship AE, Watkins PE, Rigby HS, Kenwright $J$. The role of fixator frame stiffness in the control of fracture-healing - an experimentalstudy. J Biomech 1993 Sep;26(9):1027-35.

20. Rapoff AJ, Markel MD, Vanderby R, Jr. Mechanical evaluation of transosseous wire rope configurations in a large animal external fixator. Am J Vet Res 1995 May;56(5):694-9.

21. Remiger AR. Mechanical-properties of the pinless external fixator on human tibiae. Injury 1992;23:S28-S43.

22. Stene GM, Frigg R, Schlegel U, Swiontkowski M. Biomechanical evaluation of the pinless external fixator. Injury 1992;23:S9-S27.

23. Oni OOA, Capper M, Soutis C. A finite-element analysis of the effect of pin distribution on the rigidity of a unilateral external fixation system. Injury 1993 Sep;24(8):525-7.

24. Holbrook JL, Swiontkowski MF, Sanders R. Treatment of Open Fractures of the Tibial
Shaft - Ender Nailing Versus External Fixation - a Randomized, Prospective Comparison. J Bone Joint Surg Am 1989 Sep;71A(8):1231-8.

25. Rittmann WW, Schibli M, Matter P, Allgower $M$. Open Fractures - long-term results in 200 consecutive cases. Clin Orthop Relat R 1979; (138):132-40.

26. Hosny G, Fadel M. Ilizarov external fixator for open fractures of the tibial shaft. Int Orthop 2003;27(5):303-6.

27. Nicoll EA. Fractures of the tibial shaft. A survey of 705 cases. J Bone Joint Surg Br 1964 Aug;46:373-87.

28. Tornetta P, 3rd, Bergman M, Watnik $N$, Berkowitz G, Steuer J. Treatment of grade-IIIb open tibial fractures. A prospective randomised comparison of external fixation and nonreamed locked nailing. J Bone Joint Surg Br 1994 Jan;76(1):13-9.

29. Kádas I, Kecskeméti Á, Melly A, Farkas T. Die Möglichkeiten zur Behandlung der Unterschenkelfrakturen mittels methodenwechsel. 1993. p. $362-7$.

30. Kádas I, Salacz T, Melly A, Kecskeméti Á, Végh $G$. Behandlungstaktik der offenen Unterschenkelbrüche: Fixateur externe versus UTN Swiss Surgery. Bern Verlag Hans Huber; 1996.

\section{Dr. István Kádas}

Péterfy Sándor Street Hospital-Clinic and Trauma Centre H-1076 Budapest, Péterfy Sándor u. 8-20.

Tel.: (+36) 1 299-7700 